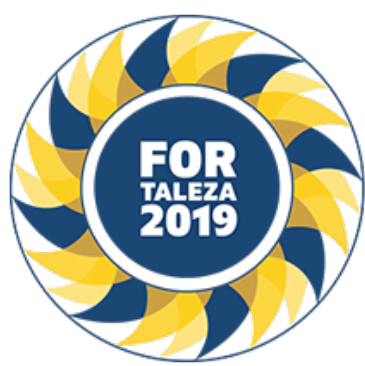

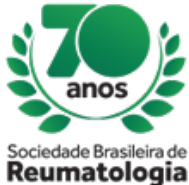

CENTRO DE EVENTOS DO CEARÁ O4 A 07 DE SETEMBRO

\title{
IMAGES OF ABNORMAL INTENSITY OF THE BONE MARROW IN THE PHALANGES OF HANDS IN A PATIENT WITH PRIMARY RAYNAUD'S PHENOMENON
}

Ravena Fontenele Belchior Cabral (Instituto Hospital de Base, brasilia, DF, Brasil), Jamille Nascimento Carneiro (Instituto Hospital de Base, Brasilia, DF, Brasil)

\section{BACKGROUND}

The Raynaud phenomenon (RP) is an exaggerated vascular response of digital vessels due to thermal (cold) and emotional stress, characterized by recurrent vasospasms causing events of pallor, cyanosis and flushing of the fingers. RP is common in the general population and usually presents with a benign clinical course. Because it is an eminently clinical diagnosis, RP has a limited number of descriptions in imaging studies. Our case is about the description of magnetic resonance imaging (MRI) findings in a female patient with a primary Raynaud phenomenon.

\section{CASE REPORT}

A 19-year-old female patient, previously healthy, with a history of excessive sensitivity to cold after exposure during rigorous winter in the Northern Hemisphere and recurrent events of RP. With arthralgias in hands in the above mentioned period. Capillaroscopy showed only an incipient SD pattern. It was performed hand MRI that showed areas of edema pattern in the periarticular bone marrow involving the proximal and distal interphalangeal joints of the first to fifth fingers of both hands (Figure 1). Laboratory tests such as Antinuclear Antibody, rheumatoid factor, sclerotic 70, inflammatory activity tests among others were within normal limits, and MRI findings can not be attributed to any other secondary pathology at the moment of evaluation. Patient evolved without rheumatologic complaints after discontinuation of exposure to cold.

\section{CONCLUSION}

The appearance of signal intensity similar to interphalangeal bone marrow edema in MRI has no specificity and can be seen in a wide variety of disorders including primary RP events. But to date, the relationship between the severity of RP and the occurrence of MRI findings in the literature has not been described either in relation to the findings of MRI with its temporal evolution and early diagnosis and treatment of rheumatic disorders potentially associated with RP. 